\title{
Cartography of emergency department visits for asthma - Targeting high-morbidity populations
}

\author{
Pierre Lajoie MD MIH FRCPC ${ }^{1}$, Andrée Laberge PhD², Germain Lebel MA MSc ${ }^{3}$, Louis-Philippe Boulet MD FRCPC FCCP4, \\ Marie Demers $\mathrm{PhD}^{5}$, Pierre Mercier MD MSc${ }^{2}$, Marie-France Gagnon $\mathrm{MA}^{2}$
}

\begin{abstract}
P Lajoie, A Laberge, G Lebel, et al. Cartography of emergency department visits for asthma - Targeting high-morbidity populations. Can Respir J 2004;11(6):427-433.
\end{abstract}

BACKGROUND: Asthma education should be offered with priority to populations with the highest asthma-related morbidity. In the present study, the aim was to identify populations with high-morbidity for asthma from the Quebec Health Insurance Board Registry, a large administrative database, to help the Quebec Asthma and Chronic Obstructive Pulmonary Disease Network target its interventions.

METHODS: All emergency department (ED) visits for asthma were analyzed over a one-year period, considering individual and medical variables. Age- and sex-adjusted rates, as well as standardized rate ratios related to the overall Quebec rate, among persons zero to four years of age and five to 44 years of age were determined for 15 regions and 163 areas served by Centres Locaux de Services Communautaires (CLSC). The areas with rates 50\% to 300\% higher $(\mathrm{P}<0.01)$ than the provincial rate were defined as high-morbidity areas. Maps of all CLSC areas were generated for the above parameters. RESULTS: There were 102,551 ED visits recorded for asthma, of which more than $40 \%$ were revisits. Twenty-one CLSCs and 32 CLSCs were high-morbidity areas for the zero to four years age group and five to 44 years age group, respectively. For the most part, the high-morbidity areas were located in the south-central region of Quebec. Only 47\% of asthmatic patients seen in ED had also seen a physician in ambulatory care.

CONCLUSION: The data suggest that a significant portion of the population seeking care at the ED is undiagnosed and undertreated. A map of high-morbidity areas that could help target interventions to improve asthma care and outcomes is proposed.

Key Words: Ambulatory care; Epidemiology; Health services; Public health; Surveillance

\section{La cartographie des visites à l'urgence en raison de l'asthme : Le ciblage des populations à la morbidité élevée}

\begin{abstract}
HISTORIQUE : L'éducation sur l'asthme devrait être offerte en priorité aux populations présentant la morbidité reliée à l'asthme la plus élevée. La présente étude visait à repérer les populations à la morbidité élevée en raison de l'asthme au moyen du registre de la Régie de l'assurance-maladie du Québec, une grande base de données administrative, afin d'aider le Réseau québécois de l'asthme et de la maladie pulmonaire obstructive chronique à cibler ses interventions.

MÉTHODOLOGIE : Toutes les visites à l'urgence en raison de l'asthme ont été analysées sur une période d'un an, compte tenu de variables personnelles et médicales. Les taux rajustés selon l'âge et le sexe, de même que les ratios de taux normalisés d'après le taux global au Québec, parmi les personnes de zéro à quatre ans et de cinq à 44 ans, ont été déterminés dans 15 régions et 163 secteurs desservis par les Centres locaux de services communautaires (CLSC). Les secteurs où les taux étaient de $50 \%$ à $300 \%$ plus élevés $(\mathrm{P}<0,01)$ que le taux provincial étaient définis comme des secteurs à la morbidité élevée. Des cartes de tous les secteurs des CLSC ont été produites à partir des paramètres précédents.

RÉSULTATS : On a dénombré 102551 dossiers de visites à l'urgence en raison de l'asthme, et plus de $40 \%$ d'entre elles n'étaient pas la première visite. Vingt et un CLSC et 32 CLSC représentaient des secteurs à la morbidité élevée pour les groupes de zéro à quatre ans et de cinq à 44 ans, respectivement. La plupart des secteurs à la morbidité élevée se trouvaient dans la région du centre-sud du Québec. Seulement $47 \%$ des patients asthmatiques vus à l'urgence avaient également été vus par un médecin en soins ambulatoires.

CONCLUSION : Les données indiquent qu'une grande partie de la population qui se fait soigner à l'urgence est sous-diagnostiquée et soustraitée. Une carte des secteurs à la morbidité élevée qui contribuerait à cibler les interventions afin d'améliorer les soins pour l'asthme et les issues est proposée.
\end{abstract}

\section{A} sthma is a major public health issue. In Canada, the prevalence of physician-diagnosed asthma is $8.4 \%$ (1). The 1996/1997 National Population Health Survey Asthma Supplement Survey found that $18 \%$ of individuals with active asthma had visited an emergency department (ED) at least once in the past year; $5.3 \%$ of those diagnosed with asthma required hospitalization each year (2). In the United States, the prevalence of asthma was reported to be $9.6 \%$ (3). Since 1995, the rates of hospitalization and death have decreased, while the rate of outpatient visits and ED visits have increased.
Until the present time, few comprehensive large-scale population surveillance programs for asthma have been established, rely on deaths, a rare event, and sometimes on hospitalizations. Furthermore, national, state and provincial statistics are often inadequate to use as a basis to design public health interventions for asthma at a local level $(4,6)$. The failure to provide data may explain why educational programs, which are regarded as an effective method to reduce the consequences of asthma (7-10), do not always target high-morbidity populations $(8,11,12)$. Some studies $(13,14)$ were done on geographic variations of asthma even in developed countries $(4,5)$. Existing programs frequently

${ }^{1}$ Unité de recherche en santé publique, Centre hospitalier universitaire de Québec; ${ }^{2}$ Direction de santé publique de Québec; ${ }^{3}$ Institut de santé publique du Québec; ${ }^{4}$ Institut de cardiologie et de pneumologie de l'Université Laval, Hôpital Laval; and ${ }^{5}$ Ministère de la santé et des services sociaux du Québec, Quebec City, Quebec

Correspondence and reprints: Dr Pierre Lajoie, Institut de santé publique du Québec, 945 Avenue Wolfe, Sainte-Foy, Quebec G1V 5B3. Telephone 418-650-5115 ext 5218, fax 418-654-3134, e-mail pierre.lajoie@inspq.qc.ca 


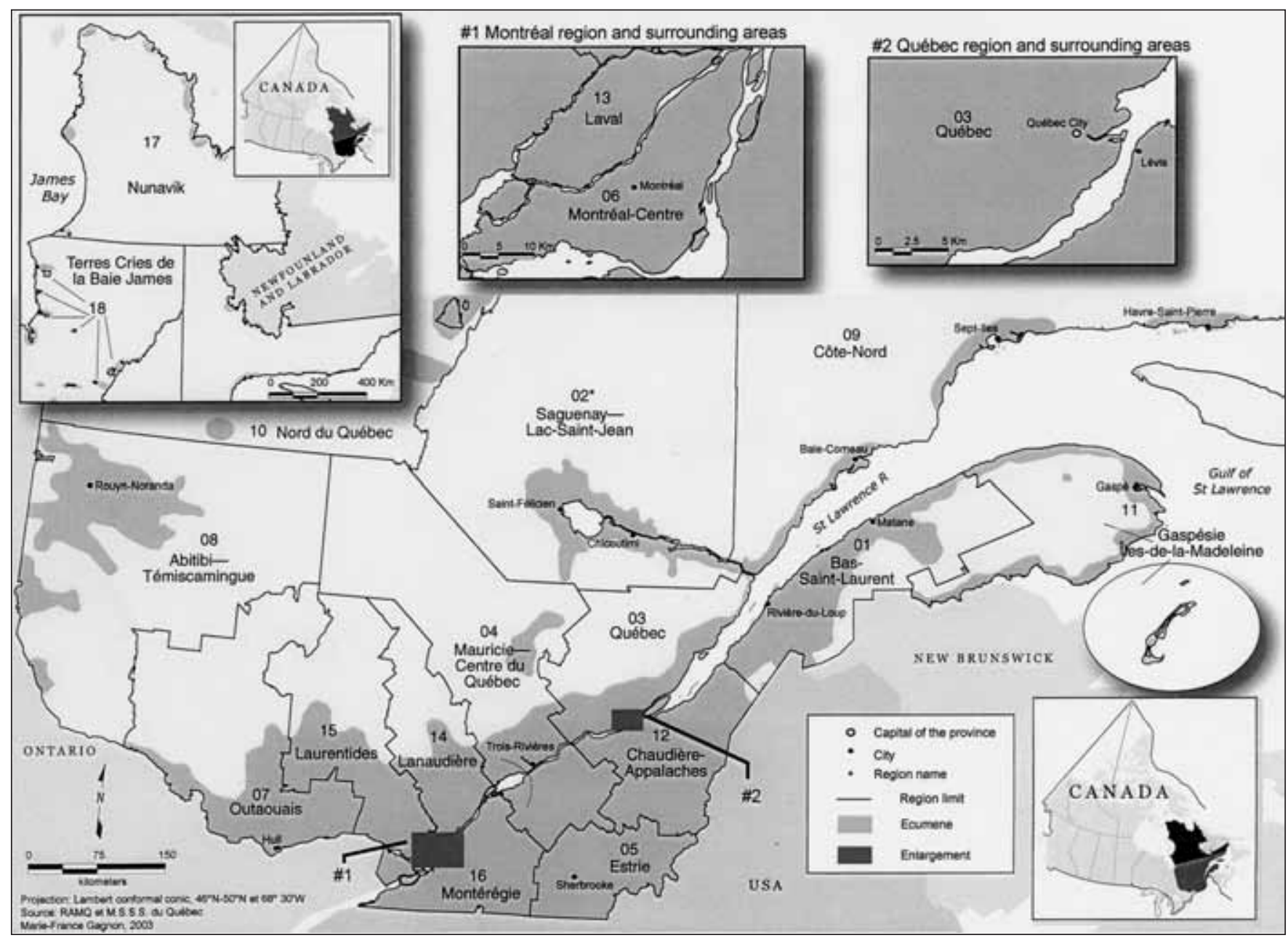

Figure 1) Health service regions in the province of Quebec

mortality and hospitalizations. Geographic information system mapping techniques have sometimes been used to study spatial variations of asthma (15). Other interventional studies in large cities were based on a community health approach: the National Cooperation Inner-City Asthma Study targeted children and the Chicago Asthma Surveillance Initiative targeted high-risk individuals $(6,16,17)$.

The Quebec Asthma and Chronic Obstructive Pulmonary Disease (COPD) Network (QACN), formerly the Quebec Asthma Education Network, created in 1994, attempted to reduce mortality and morbidity from asthma by providing education to asthmatic patients and by offering updates and support to professionals on asthma care (18). Most deaths, hospitalizations and ED visits for asthma may be avoidable $(19,20)$. A large number of ED visits are related to inadequate treatment and follow-up, as well as a lack of compliance to therapy $(21,22)$. Acute asthma exacerbations in patients seen in EDs are often severe and life-threatening (23).

ED visits represent an early indicator for the surveillance of asthma in populations. We believe that the frequency of ED visits can vary from one area to another and can be used to identify problem areas. Monitoring systems based on respiratory ED admissions are highly reliable for epidemiological purposes (24). To our knowledge, no study has been based on a large administrative database, covering an entire population, examining ED visits for asthma, which is a frequent morbid event. We conducted a one-year study involving all hospitals with an ED in the province of Quebec to identify high-morbidity areas for asthma-related ED visits and provide data to the QACN to help develop focused programs and interventions targeted at groups at risk based on known risk factors such as age, sex and multiple visits to EDs.

\section{Population of Quebec}

\section{METHODS}

The present study was done on the entire population of Quebec, which was 7,410,504 in 2001. Quebec includes 18 health-service regions, in which there is a total of 163 community health centre areas (Centres Locaux de Services Communautaires [CLSC]) (Figure 1). The population covered by the CLSC ranges from approximately 50,000 in rural areas to 100,000 in urban areas. Nunavik (\#17), James Bay (\#18) and northen Quebec regions (38,575 inhabitants) were excluded because of the lack of individual data related to ED services.

\section{Data collection}

The dependant health variable was ED visits for asthma. The inclusion criteria for cases were diagnosis of asthma based on the 
ninth revision of the International Classification of Diseases (25) (ICD-9: 493) or bronchospasm (ICD-9: 519.1) stated by physicians in medical records. Health data were obtained from the Quebec Health Insurance Board (QHIB) Registry. Population data were obtained from Statistics Canada (Census 1991 through the Quebec Department of Health [26]). Hospital accessibility index (HAI) and socioeconomic indicators were obtained from the Quebec Department of Health. HAI was defined as the ratio of consumption of hospital resources by the population of the CLSC area over mean consumption of these resources in the province.

Considering the public health objectives of the present study, the diagnosis of bronchospasm was included to take into account the burden of the disease in younger children. Bronchiolitis with bronchospasm is frequent among very young children. Other personal variables included year of the event, sex, residency (region and CLSC) and age at mid-year. The encrypted QHIB number made it possible to calculate the number of events for an individual in the same year. Data on office and outpatient clinic visits, and the number and type of specialist visits, were also gathered.

Since 1996, computerized billing of visits by physicians is more than $90 \%$ comprehensive and diagnosis is present on more than $88 \%$ of the payment requests. The year 1996 was chosen because data on ED visits were the most complete in that year and were not influenced by the ambulatory care reform, which started in 1997. In Quebec, a fee for services paid by the QHIB was the usual mode of payment for ED medical services. In 1996, more than 95\% of ED medical services were paid by that mode.

\section{Statistical analysis}

Two frequency measures were calculated: number and agestandardized rates of ED visits for the province of Quebec. Agestandardized rates were also calculated by sex for regions and CLSC areas. Age- and sex-standardized rates were calculated using the direct method. To compare the frequency of ED visits between areas, the standardized rate ratio (SRR) was used, which was defined as the ratio of the age-standardized rate of an area (region or CLSC) over the age-standardized rate for the entire population of Quebec. The statistical significance of SRRs was calculated using variance developed elsewhere (27-29). SAS version 8.0 (SAS Institute, USA) was used for all analyses. Statistical significance of $\mathrm{P} \leq 0.01$ was employed to minimize the risk of obtaining spurious results because of multiple statistical tests.

Rates were established using two age groups: zero to four years of age and five to 44 years of age. The 45 years of age and older age group was excluded because of the high risk of misclassification with COPD. The coefficient of variation (CV) of the agestandardized rates were also calculated. The CVs were used to measure the stability of the age-standardized rates of an area and were classified as unstable (CV greater than 33.3\%), moderately stable (CV greater than $16.6 \%$ and less than $33.3 \%$ ) and stable (less than $16.6 \%$ ). To compare regions according to the adjusted rates in graphs, SRRs were transformed to represent relative differences (\%) between the rate of the region and the rate of the province. CLSC high-morbidity and low-morbidity areas were defined as those areas for which there were sufficient data, where SRRs of ED visits were significatively different and were at least $50 \%$ higher and lower than the provincial rate, respectively. The areas must then have met the following criteria: $S R R=1.5$ or $\mathrm{SRR}=0.67$, CV less than $16.6 \%$ and $\mathrm{P}=0.01$. Pearson's coefficient of correlation between ED visit rates, HAI and level of
TABLE 1

Relative frequency of emergency department visits for asthma, by age, number of visits and revisits

\begin{tabular}{lcccc}
$\begin{array}{l}\text { Number } \\
\text { of visits }\end{array}$ & $\begin{array}{c}\mathbf{0} \text { to } \mathbf{4} \text { years } \\
\mathbf{n}(\%)\end{array}$ & $\begin{array}{c}\mathbf{5} \text { to } \mathbf{4 4} \text { years } \\
\mathbf{n}(\%)\end{array}$ & $\begin{array}{c}\mathbf{4 5} \text { years }+ \\
\mathbf{n}(\%)\end{array}$ & $\begin{array}{c}\text { Total } \\
\mathbf{n}(\%)\end{array}$ \\
\hline 1 & $9429(35.3)$ & $22,259(40.9)$ & $9866(46.0)$ & $41,464(40.4)$ \\
$2+$ & $17,246(64.7)$ & $32,249(59.3)$ & $11,592(54.0)$ & $61,087(59.6)$ \\
Total & $26,675(100.0)$ & $54,418(100.0)$ & $21,458(100.0)$ & $102,551(100.0)$ \\
Revisits* & $11,564(43.4)$ & $21,868(40.2)$ & $7778(36.2)$ & $41,210(40.2)$ \\
\hline
\end{tabular}

*All emergency department visits except the first visit

socioeconomic status by CLSC area was calculated. The P of the correlation coefficient was adjusted for spatial autocorrelation (30).

A map of CLSC areas according to the level of SRR was generated using MapInfo Professional V4.52 software (MapInfo Corporation, USA). Each CLSC area was classified according to the level of SRR, based on the seven-grade Monson risk classification (31).

\section{ED visits for asthma}

\section{RESULTS}

In 1996, there were 102,551 ED visits for asthma in Quebec (Table 1). During that year, repeat visits (ie, multiple visits among the same individuals), excluding the first visit, accounted for $40 \%$ of total visits. Revisits were included in the analyses. The proportion of revisits decreased with age: $43.4 \%$ (zero to four years of age), $40.2 \%$ (five to 44 years of age) and $36.2 \%$ (45 years of age and older). Among those zero to four years of age, the proportion of revisits was higher in boys (44.6\%) than in girls $(41.0 \%)$; among those five years of age and older, the proportion was higher in girls. The proportion of revisits was higher in high-morbidity CLSC areas (43.8\%) than in low-morbidity CLSC areas $(34.9 \%)$. The crude rate of ED visits for asthma was 1409/100,000 person-years. Age-specific rates of ER visits were higher in the younger age group (Figure 2). The age-standardized rates were $5786 / 100,000$ person-years among those zero to four years of age and 1253/100,000 person-years among those five to 44 years of age.

\section{Geographical variation among regions and CLSCs}

Zero to four years old: In 1996, regional rates per 100,000 ranged from 3247 to 7959 . Five regions had rates higher than the provincial rate $(\mathrm{P}<0.01)$ and 10 had lower rates $(\mathrm{P}<0.01)$ (Figure 3). Thirty-eight CLSC areas had higher rates than the provincial rate $(\mathrm{P}<0.01)$. These CLSCs were concentrated in the southwestern part of Quebec. Twenty-one of these CLSCs were high-morbidity areas (Figure 4). For the most part, they were located in the southcentral part of Quebec: Montreal, Outaouais, Monteregie and Estrie. Most of the areas were urban. Fifty-three areas had lower age-standardized rates $(\mathrm{P}<0.01)$. One-half were located in the central part of Quebec and the others were dispersed elsewhere in the province.

Five to 44 years old: Regional rates per 100,000 ranged from 769 to 1739 . Seven regions had rates higher than the provincial rate $(\mathrm{P}<0.01)$ (Figure 5$)$. Four regions had rates lower than the provincial rate $(\mathrm{P}<0.01)$. Fifty-four CLSC areas had higher rates $(\mathrm{P}<0.01) ; 32$ were high-morbidity areas (Figure 6). These areas were concentrated in Montreal, Estrie, Monteregie 


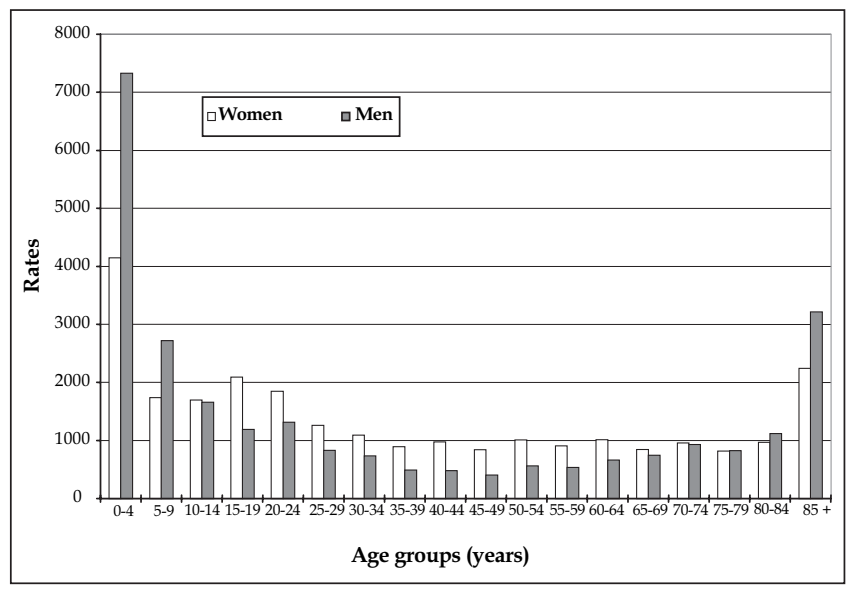

Figure 2) Emergency department visit rates $(\times 100,000$ person-years $)$ for asthma, by age and sex in Quebec

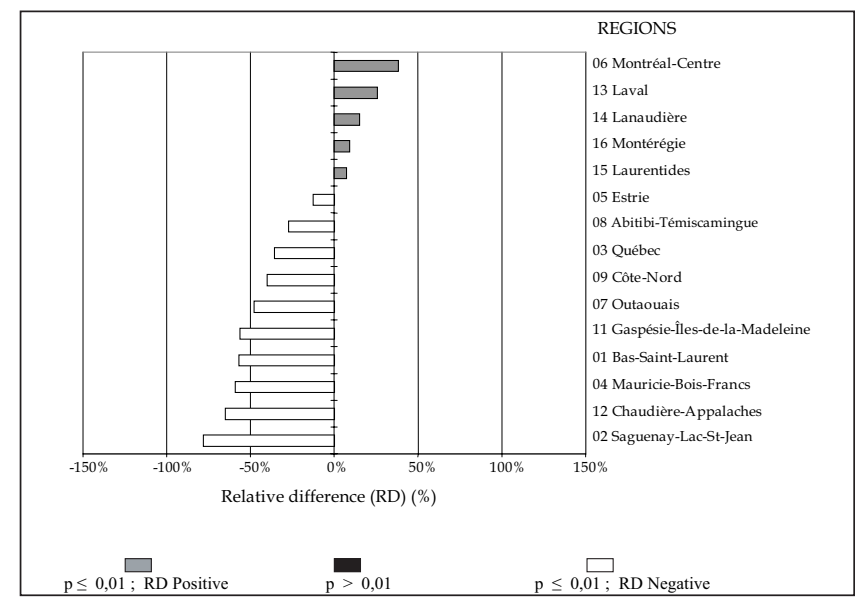

Figure 3) Differences between the rate of each region and the rate of the province regarding emergency department visits for asthma in persons zero to four years of age

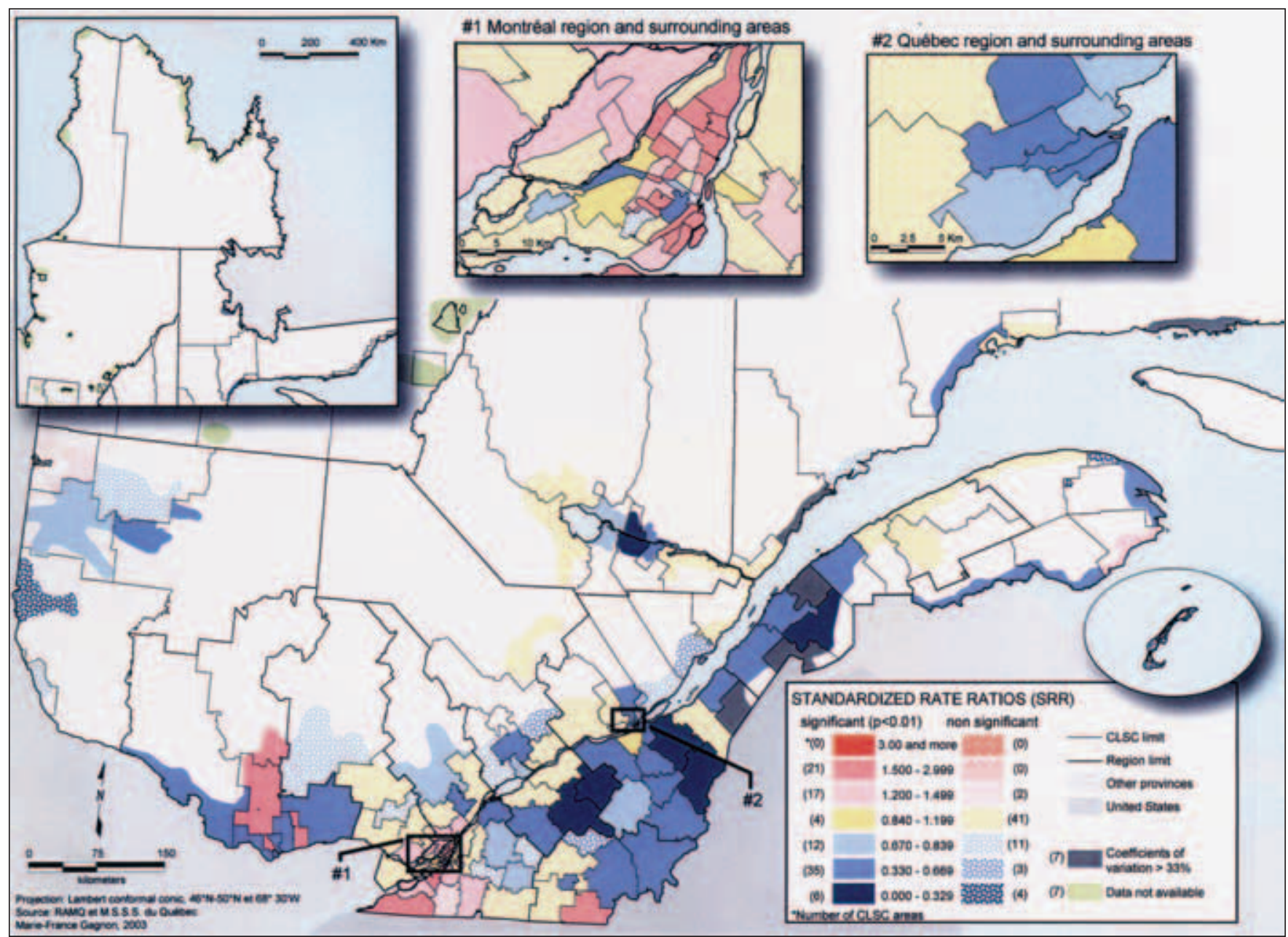

Figure 4) High-morbidity Centres Locaux de Services Communautaires (CLSC) areas for persons zero to four years of age

and the Outaouais regions. However, one-half were dispersed in other rural or semiurban areas of the province. Thirty-two areas had lower rates than the provincial rate, one-half of which were also located in the central part of Quebec.

Role of socioeconomic status: No association was found between high ED visit rate and access to hospital resources by
CLSC area. The results suggested that the frequency of ED visits for asthma among persons zero to four years of age and five to 44 years of age was related to socioeconomic status (Table 2). In both age groups, these rates were higher in CLSC areas where there was a higher percentage of low income individuals, single-parent families and persons on social assistance. In the 


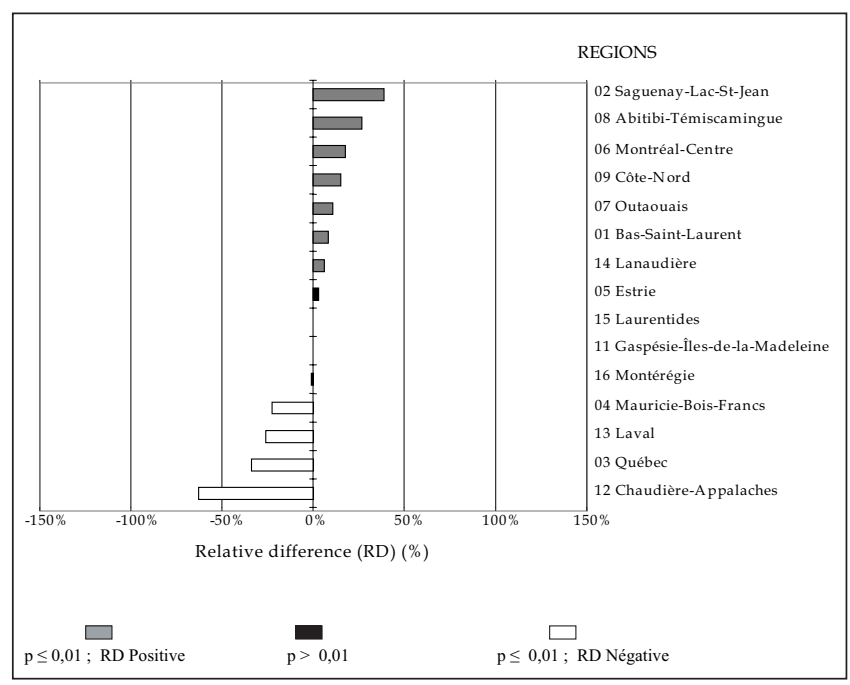

Figure 5) Differences between the rate of each region and the rate of the province regarding ED visits for asthma for persons five to 44 years of age

five to 44 years age group, low mean family income was also correlated with higher ED visit rates.

Medical treatment: In 1996, only 47\% of asthmatic patients with at least one ED visit for asthma had seen a physician at his/her office or at an outpatient clinic for asthma. The proportion was higher among persons zero to four years of age (55.1\%) than among those five to 44 years of age $(45.8 \%)$ and those 45 years and older $(41 \%)$. There was no difference between high-morbidity and low-morbidity CLSC areas. However, the proportion of patients who had seen a physician in their office was lower in high-morbidity areas (35.9\% versus $40.0 \%)$. The proportion decreased with age until 45 years of age: $63.2 \%$ (zero to four years of age), $47.3 \%$ (five to 14 years of age), $20.3 \%$ ( 15 to 44 years of age) and $25.3 \%$ (45 years of age and older). Only $37 \%$ of asthmatic patients had seen a specialist. Most patients younger than 15 years of age had seen a pediatrician. Overall, only $10.6 \%$ had seen a lung specialist.

\section{DISCUSSION}

We used the large QHIB database to gather data on all ED visits for asthma in Quebec over a one-year period. Region and CLSC age- and sex-standardized ED visit rates were compared using SRRs. We found highly significant differences between areas. Areas classified as high-morbidity areas had age-standardized rates $50 \%$ to $300 \%$ higher than the rate of the province. The method that we used, based on direct standardization and SRR, allowed us to compare and rank regions and CLSC areas, unlike indirect methods using standardized mortality ratios and the comparative morbidity index.

In the present study, the rates may have been underestimated due to possible underreporting of cases by physicians not paid through the fee-for-service method, but this underreporting from the QHIB database represents less than 5\% of cases. In our study, the definition of cases was based on diagnoses made by the physician in charge at the ED. A physician's diagnosis of asthma is recognized as a valid source in epidemiological studies and surveys, particularly among middle-aged people (32). Bronchospasm is frequent in children younger than five years of age, particularly in relation with infectious respiratory diseases,
TABLE 2

\section{Spatial correlations for Centres Locaux de Services Communautaires areas between the rates of the emergency department visits and socioeconomic indicators}

\begin{tabular}{lrrrr}
\hline \multirow{2}{*}{ Indicators } & \multicolumn{2}{c}{$\mathbf{0}$ to $\mathbf{4}$ years old } & \multicolumn{3}{c}{$\mathbf{5}$ to $\mathbf{4 4}$ years old } \\
\cline { 2 - 5 } & \multicolumn{1}{c}{$\mathbf{r}^{*}$} & \multicolumn{1}{c}{$\mathbf{P}^{\dagger}$} & $\mathbf{r}^{*}$ & $\mathbf{P}^{\dagger}$ \\
\hline Hospital accessibility index & -0.30 & 0.10 & -0.03 & 0.73 \\
Mean family income & -0.03 & 0.79 & -0.20 & $<0.01$ \\
Individuals with low income (\%) & 0.36 & $<0.01$ & 0.26 & $<0.01$ \\
Unemployment rate (\%) & -0.01 & 0.39 & 0.07 & 0.35 \\
Individuals without high school (\%) & -0.12 & 0.49 & 0.07 & 0.40 \\
Children under 18 in single-parent & 0.47 & $<0.01$ & 0.39 & $<0.001$ \\
$\quad$ home (\%) & & & & \\
Individuals on social assistance (\%) & 0.26 & $<0.01$ & 0.33 & $<0.001$ \\
\hline
\end{tabular}

${ }^{*}$ Pearson's coefficient of correlation; ${ }^{\dagger}$ Adjusted for spatial autocorrelation

but may not indicate the presence of persistent asthma. The zero to four years age group was retained, even if the diagnosis was less valid, because the relative frequency of ED visits for bronchospasm and asthma was high in this group. For people older than 45 years, diagnosis was also less certain because of a higher prevalence of COPD (33). The potential bias related to possible misclassification of asthma in young children and older people was minimized by using the five to 44 years age group to measure the frequency of ED visits. The validity of recording asthma diagnoses was estimated to be $80 \%$ in health care data files and medical charts (34). General practice morbidity data for asthma were evaluated as good sources (35). The inclusion of bronchospasm may have led to an overestimation of the frequency of ED visits for asthma in all CLSC areas, particularly among zero- to four-year-olds, but did allow us to describe the burden of the disease in ED departments. The comparison among regions and CLSCs was not influenced by this potential nondifferential bias and remains valid. We cannot exclude a potential bias due to a variability of the diagnosis of asthma among different hospitals even if the organization of emergency health services in Quebec is uniform and medical training is quite similar. However, the effect of this bias is minimized by the fact that asthmatic patients in our study visited EDs of their choice often outside their own CLSC area.

A limited number of CLSCs were high-morbidity areas. ED visit rates are indicators of health service consumption. They represent an indirect indicator of the incidence or prevalence of asthma in a population. These results should be interpreted with caution. Higher rates of ED visits were reported among patients with low socioeconomic status (36). However, the correlations that we found with some socioeconomic indicators have some limitations. Because these indicators relate to group data of CLSC areas and not to individuals, the possibility that the asthmatics who visited ED in high-morbidity areas might be different from the low income group cannot be ruled out. Accessibility to health services may also influence ED service use (36). We found no association between high ED visit rates and access to hospital resources by CLSC areas. The proportion of patients who had seen a physician in their office was lower in 


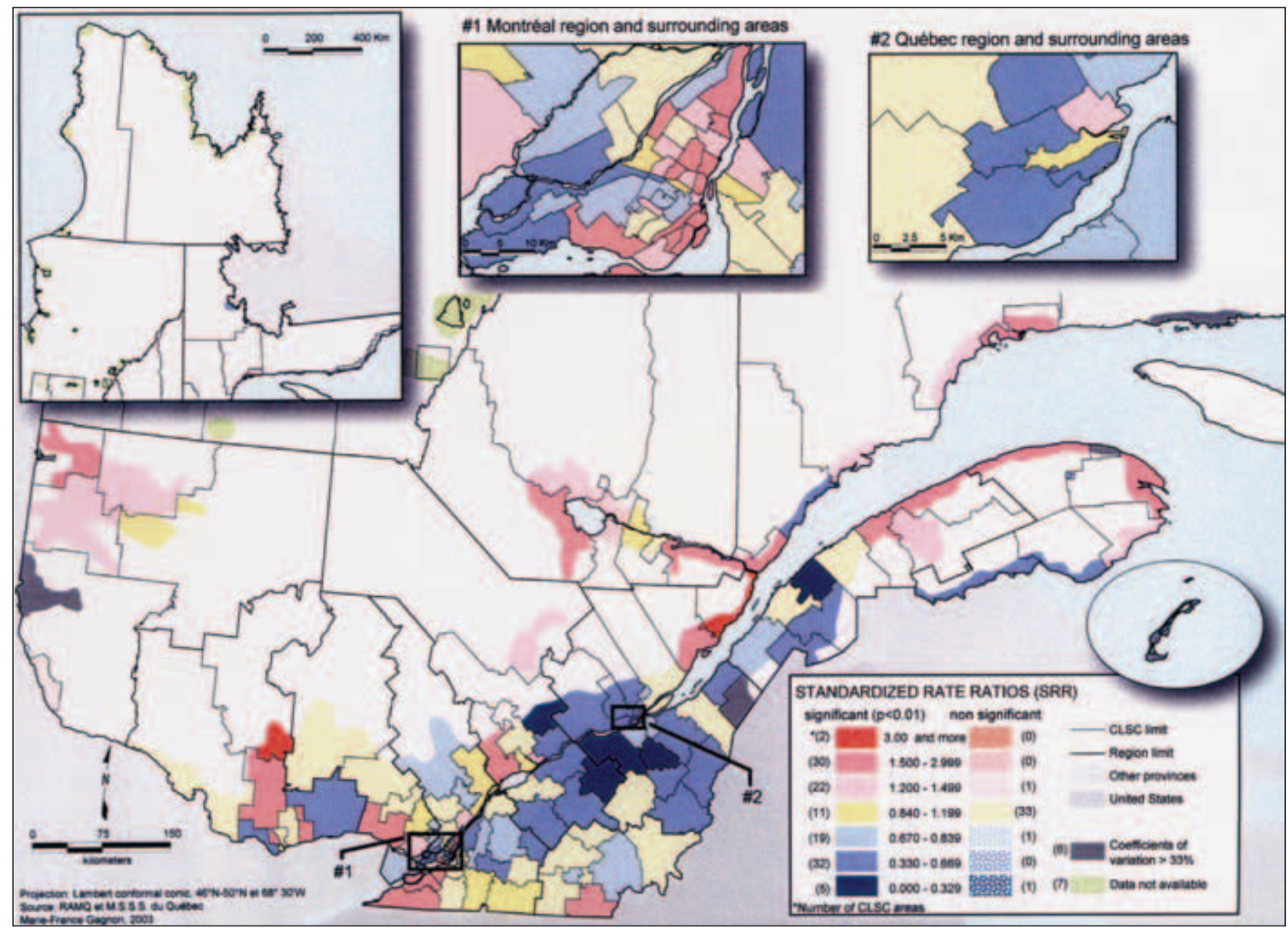

Figure 6) High-morbidity Centres Locaux de Services Communautaires (CLSC) areas for persons five to 44 years of age

high-morbidity areas. We did not study the association with access to primary care physicians, which may be a plausible explanation. The office and CLSC accessibility index, recently developed in Quebec, will allow us to investigate this further in the future.

Our data suggest that a significant proportion of the population seeking care at the ED may be undiagnosed and undertreated $(37,38)$. For the zero to four years age group, the concentration of high-morbidity areas in the south-central region of the province raises the question of the role of potential nonmedical, environmental or other factors. Lower ED visit rates in some other regions may be explained by the fact that the QACN has been well-established in those regions for a longer time. Regardless of whether their rankings were high or low, the cartography results were appreciated by the CLSCs and the regions, and used for the development of local programs against asthma.

\section{CONCLUSION}

The epidemiological methods developed in the present population-based study allowed us to make valid comparisons among regions and CLSCs regarding rates of ED visits for asthma. In a first step, the cartography of asthma in Quebec helps point out high-morbidity areas and populations. ED data are useful to capture undiagnosed and undertreated asthma in a population. In line with the objectives of the study, from a public health perspective, the results for both age groups allowed the QACN to target their interventions. To provide specific data and maps was a great motivational tool for local hospital and department managers, physicians and educators. In a second step, we tried to reach subgroups of the population of asthmatics; particularly, patients with multiple visits to $\mathrm{ED}$. Because the ambulatory care reform is now over, the cartography could be repeated for evaluation purposes and should include population-based data on medication.

The generalization of our results to other populations is limited by sociodemographic characteristics and the type of health service organization. Quebec is part of the Canadian Medicare system that covers almost all hospital and medical expenses. Finally, the approach laid out in our study, based on the comparison of SRRs, can be applied to other settings or diseases for policy planning and program assessment.

ACKNOWLEDGEMENT: The study was created as a part of the program "Towards excellence in asthma managment" (TEAM) of the Quebec Asthma and Chronic Obstructive Pulmonary Disease Network (QACN).

FUNDING: The study was supported by a grant from Merck Frosst Canada. 


\section{REFERENCES}

1. Canadian Institute for Health Information, Canadian Lung Association, Heath Canada, Statistics Canada. Respiratory Disease in Canada, publication H39-593/2001E. Ottawa: Health Canada, 2001.

2. National population health survey: Asthma supplementary survey. 1996-97. Ottawa: Statistics Canada, 1998.

3. Mannino DM, Homa DM, Akinbami LJ, Moorman JE, Gwynn C, Redd S. Surveillance for asthma - United States, 1980-1999. MMWR Surveill Summ 2002;51:1-13.

4. Mannino DM, Homa DM, Pertowski CA, et al. Surveillance for asthma - United States 1960-1995. MMWR CDC Surveill Summ 1998;47:1-27.

5. National Asthma Control Task Force. The Prevention and Management of Asthma in Canada, publication H49-138/2000E. Ottawa: Health Canada, 2000.

6. Weiss KB, Grant EN. The Chicago Asthma Surveillance Initiative: A community-based approach to understanding asthma care. Chest 1999;116:141S-5S.

7. Gibson PG, Powell H, Coughlan J, et al. Limited (information only) patient education programs for adults with asthma. Cochrane Database Syst Rev 2000;2:CD001005.

8. Boulet LP. Asthma education: What has been its impact? Can Respir J 1998;5(Suppl A):91A-6A.

9. de Oliveira MA, Bruno VF, Ballini LS, BritoJardim JR, Fernandez AL. Evaluation of an educational program for asthma control in adults. J Asthma 1997;34:395-403.

10. Cote J, Cartier A, Robichaud P, et al. Influence on asthma morbidity of asthma education programs based on self-management plans following treatment optimization. Am J Respir Crit Care Med 1997;155:1509-14.

11. Garrett J, Fenwick J, Taylor G, Mitchell E, Stewart J, Rea H. Prospective controlled evaluation of the effect of a community based asthma education center in a multiracial working class neighbourhood. Thorax 1994;49:976-83.

12. Bolton MB, Tilley BC, Kuder J, Reeves T, Schultz LR. The cost and effectiveness of an education program for adults who have asthma. J Gen Intern Med 1991;6:401-7.

13. Weiss KB, Wagener DK. Geographic variations in US asthma mortality: Small-area analyses of excess mortality, 1981-1985. Am J Epidemiol 1990;132:S107-15.

14. De Palo VA, Mayo PH, Friedman P, Rosen MJ. Demographic influences on asthma hospital admission rates in New York City. Chest 1994;106:447-51.

15. English P, Neutra R, Scalf R, Sullivan M, Waller L, Zhu L. Examining associations between childhood asthma and traffic flow using a geographic information system. Environ Health Perspect 1999;107:761-7.

16. Mitchell H, Senturia Y, Gergen P, et al. Design and methods of the National Cooperative Inner-City Asthma Study. Pediatr Pulmonol 1997;24:237-52.

17. Addington WW, Weiss KB. Targeting asthma in Chicago: community stories. Chest 1999;116(Suppl 1):198S.

18. Boulet LP, Chapman KR. Asthma education: The Canadian experience. Chest 1994;106(Suppl):202S-10S.

19. Blainey AD, Beale A, Lomas D, Partridge MR. The cost of acute asthma - how much is preventable? Health Trends 1990-91;22:151-3.
20. Sly RM. Effects of treatment on mortality from asthma. Ann Allergy 1986;56:207-12.

21. Adams RJ, Smith BJ, Ruffin RE. Factors associated with hospitalizations and repeat emergency department visits for adults with asthma. Thorax 2000;55:566-73.

22. Hanania NA, David-Wang A, Kesten S, Chapman KR. Factors associated with emergency department dependence of patients with asthma. Chest 1997;111:290-5.

23. Salmeron S, Liard R, Elkarrat D, Muir JF, Neukirch F, Ellrodt A. Asthma severity and adequacy of management in accident and emergency departments in France: A prospective study. Lancet 2001;358:629-35.

24. Martinez F, Sunyer J, Anto JM. Reliability of a monitoring system for respiratory emergency room admissions. Eur Respir J $1993 ; 6: 337-41$

25. World Health Organization. International Classification of Diseases, 9th revision. Geneva: World Health Organization, 1978.

26. Pelletier G. La population du Québec par territoire de CLSC, de DSC et de RSS, pour la periode 1981 à 2016. Québec: Service de l'analyse statistique, Direction des indicateurs de résultats et de l'information statistique, Ministère de la Santé et de Services sociaux, 1996.

27. Estève J, Benhamou E, Raymond L. Statistical Methods in Cancer Research, Volume IV, Descriptive Epidemiology, publication No 128. Lyon: International Agency for Research on Cancer (IARC), 1994.

28. Bouyer J, Hémon D, Cordier S, et al. Épidémiologie: Principes et Méthodes Quantitatives. Paris: Éditions INSERM, 1993.

29. Breslow NE, Day NE. Statistical Methods in Cancer Research, Volume II - The Design and Analysis of Cohort Study. Lyon: International Agency for Research on Cancer. New York: Oxford University Press, 1987:406.

30. Wakefield JC, Kelsall JE, Morris SE. Clustering, cluster detection and spatial variation in risk. In: Elliott P, Wakefield JC, Best NG, Briggs DJ, eds. Spatial Epidemiology. Methods and Applications. New York: Oxford University Press, 2000:128-52.

31. Monson RR. Occupational epidemiology. Boca Raton: CRC Press, 1980:94.

32. Toren K, Brisman J, Jarsholm B. Asthma and asthma-like symptoms in adults assessed by questionnaires. A literature review. Chest 1993;104:600-8.

33. Bennett J, Osman J, Blainey AD, Davies RJ. The assessment of a computer administered questionnaire in the differential diagnosis of asthma and chronic airflow limitation. Br J Dis Chest 1988;82:268-73.

34. Rawson NS, Malcolm E. Validity of the recording of ischaemic heart disease and chronic obstructive pulmonary disease in the Saskatchewan health care datafiles. Stat Med 1995;14:2627-43.

35. Hollowel J. The General Practice Reseach Database: Quality of morbidity data. Popul Trends 1997;87:36-40.

36. Jones AP, Bentham G, Harrison BD, Jarvis D, Badminton RM, Wareham NJ. Accessibility and health service utilization for asthma in Norfolk. Engl J Pub Health Med 1998;20:312-7.

37. Tough SC, Hessel PA, Green F, et al. Factors that influence emergency department visits for asthma. Can Respir J 1999;6:429-35.

38. Dales R, Schweitzer I, Kerr P, Gougeon L, Rivington R, Draper J. Risk factors for recurrent emergency department visits for asthma. Thorax 1995;50:520-4. 


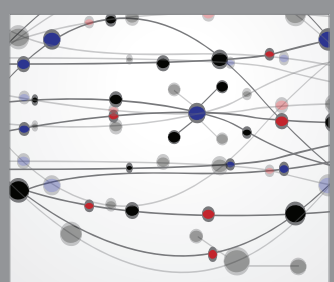

The Scientific World Journal
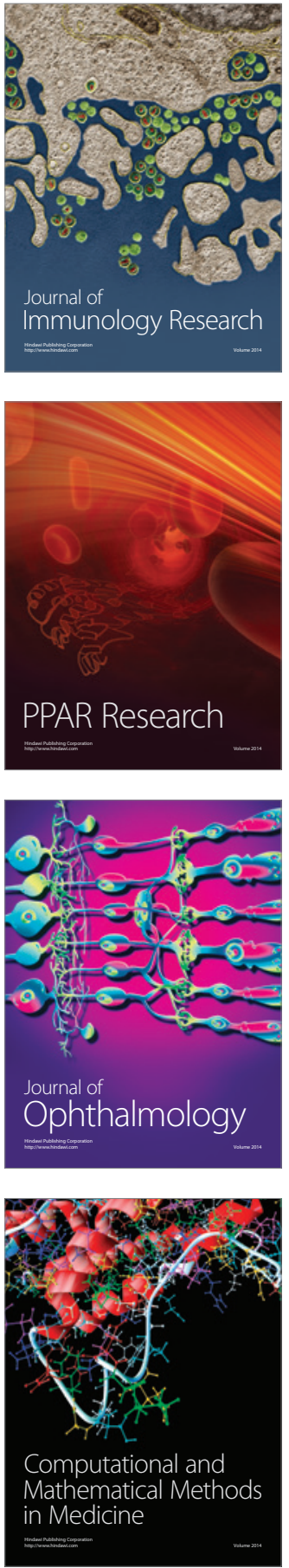

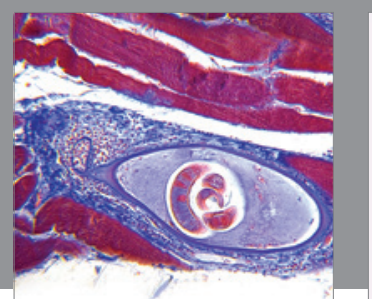

Gastroenterology Research and Practice

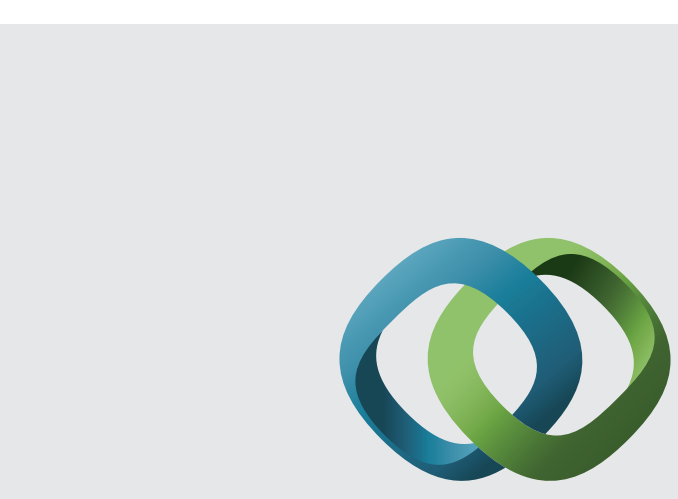

\section{Hindawi}

Submit your manuscripts at

http://www.hindawi.com
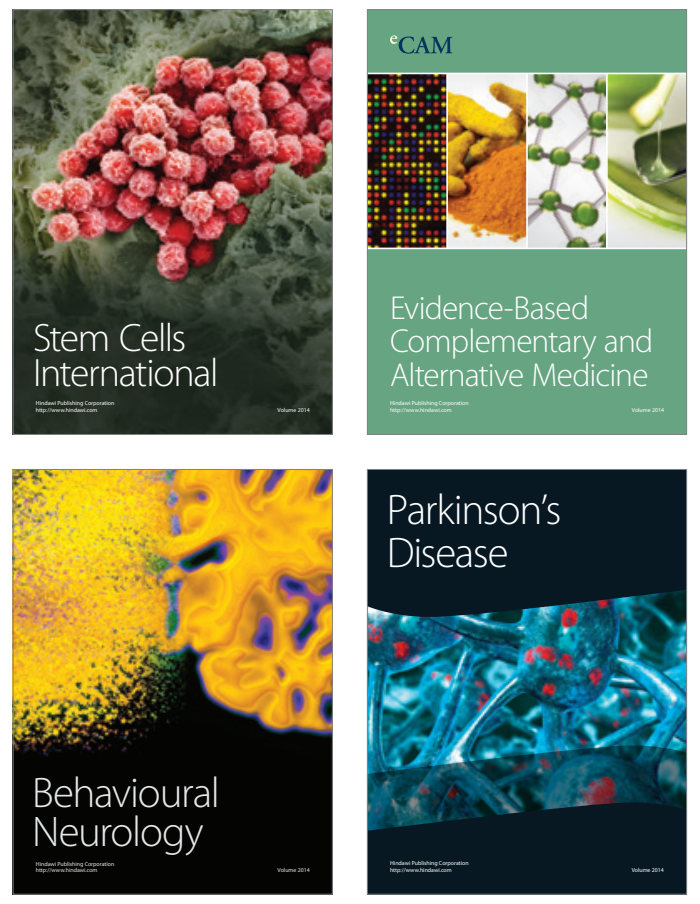
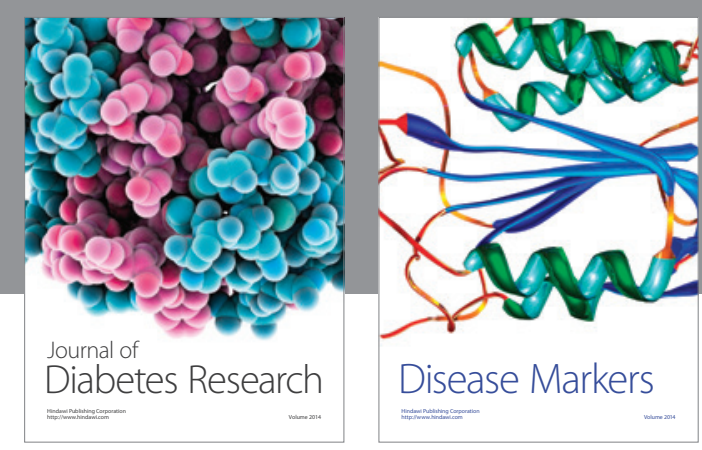

Disease Markers
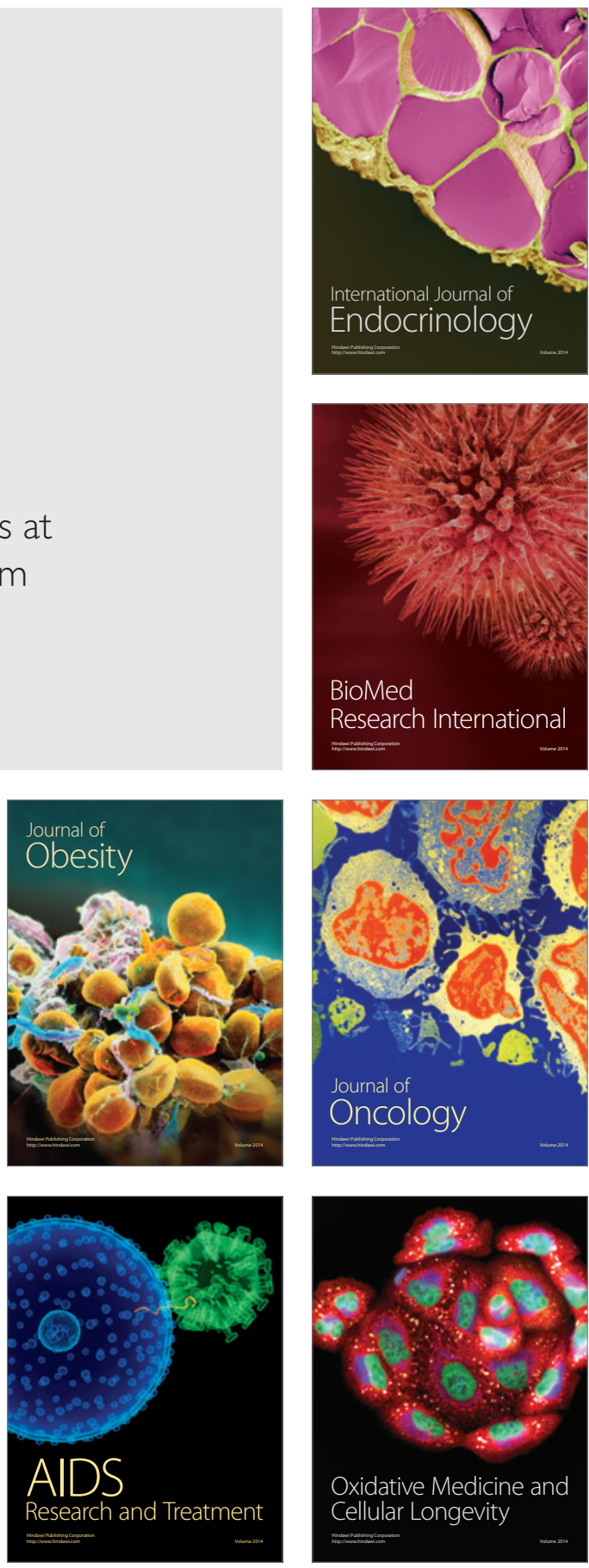